\title{
Ventriculovascular interactions late after atrial and arterial repair of transposition of the great arteries
}

\author{
Giovanni Biglino, PhD, ${ }^{\mathrm{a}, \mathrm{b}}$ Hopewell Ntsinjana, MD, ${ }^{\mathrm{a}, \mathrm{b}}$ Carla Plymen, MD, ${ }^{\mathrm{b}}$ Oliver Tann, MD, \\ Alessandro Giardini, MD, ${ }^{\mathrm{b}}$ Graham Derrick, MD, ${ }^{\mathrm{b}}$ Kim H. Parker, PhD, ${ }^{\mathrm{c}}$ Victor Tsang, MD, \\ Silvia Schievano, $\mathrm{PhD},{ }^{\mathrm{a}, \mathrm{b}}$ and Andrew M. Taylor, $\mathrm{MD}, \mathrm{PhD}^{\mathrm{a}, \mathrm{b}}$
}

\begin{abstract}
Objective: The aim of this study was to compare atrial switch and arterial switch operations for the repair of transposition of the great arteries (TGA), assessing cardiac function and ventriculoarterial (VA) coupling based on cardiac magnetic resonance (CMR) data. Using CMR-derived wave intensity analysis, this study provides a noninvasive comparison of the 2 systemic ventricles and evaluates the subclinical hemodynamic burden of these operations.
\end{abstract}

\begin{abstract}
Methods: Fifty-four patients (18 controls, 18 atrial switches, 18 arterial switches) were studied. Dimensional and functional data, including the ejection fraction (EF) and end-diastolic volume, were derived from CMR, as well as aortic distensibility. Wave intensity was computed from CMR according to a formulation based on changes in area and velocity, and the peaks of the 2 major systolic waves (forward compression wave $[\mathrm{FCW}]$, and forward expansion wave $[\mathrm{FEW}]$ ) were measured as indicators of ventricular function.
\end{abstract}

Results: Both switches exhibited significantly increased end-diastolic volume and enlarged aortic root areas, and atrial switches were also characterized by significantly lower EF. Patients with TGA presented stiffer ascending aortas, particularly those repaired with an arterial switch. Both FCW and FEW were significantly lower in both TGA cohorts than the controls, suggesting compromised VA coupling, likely a result of increased impedance caused by the stiffer ascending aorta. A significant difference between switch type was noticed in terms of the FEW peak, which was lower in the atrial switch group.

Conclusions: These data highlight reduced aortic distensibility and abnormal VA coupling in repaired TGA. An intraoperational difference was noted in terms of EF and peak FEW, likely reflecting the different nature of the subaortic ventricle. (J Thorac Cardiovasc Surg 2014;148:2627-33)

Historically, atrial redirection methods (Mustard and Senning operations ${ }^{1-3}$ ) were used routinely for surgical palliation of transposition of the great arteries (TGA). These were subsequently replaced by the current arterial switch operation (ASO), ${ }^{4-6}$ which offered improved long-

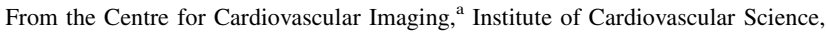
University College London, London, United Kingdom; Cardiorespiratory Unit, ${ }^{\text {b }}$ Great Ormond Street Hospital for Children, NHS Foundation Trust, London, United Kingdom; and Department of Bioengineering, ${ }^{\mathrm{c}}$ Imperial College, London, United Kingdom.

This study was supported by the UK National Institute of Health Research (NIHR; grant no. PDF-2012-05-430), Fondation Leducq (grant no. 09 CVD 04), 2012 Commonwealth Scholarship S Africa, Royal Academy of Engineering/Engineering and Physical Sciences Research Council (grant no. 10216/79). This report is independent research by the National Institute for Health Research Biomedical Research Centre Funding Scheme. The views expressed in this publication are those of the authors and not necessarily those of the NHS, the National Institute for Health Research, or the Department of Health.

Disclosures: Graham Derrick reports lecture fees from St. Jude Medical. Andrew Taylor reports grant support from Siemens Medical Solution. All other authors have nothing to disclose with regard to commercial support.

G. Biglino and H. Ntsinjana contributed equally to the study.

Received for publication Feb 3, 2014; revisions received May 27, 2014; accepted for publication July 31, 2014; available ahead of print Sept 12, 2014.

Address for reprints: Giovanni Biglino, $\mathrm{PhD}$, Centre for Cardiovascular Imaging, Level 6 Nurses Home, Great Ormond Street Hospital for Children, Great Ormond St, London, WC1N 3JH, United Kingdom (E-mail: g.biglino@ucl.ac.uk). $0022-5223 / \$ 36.00$

Copyright (c) 2014 by The American Association for Thoracic Surgery http://dx.doi.org/10.1016/j.jtcvs.2014.07.072 term survival. ${ }^{7}$ However, despite the success of the ASO, several studies have shown varying long-term complications with both strategies. The ascending aorta has recently been shown to present with nonprogressive dilatation and reduced distensibility. ${ }^{8}$ Aortic wall abnormalities have been found even in unrepaired TGA due to intrinsic congenital structural abnormalities of the aortic media detected on histologic studies. ${ }^{9,10}$ Consequently, increased arterial stiffness could result in abnormal ventriculoarterial (VA) coupling with hemodynamic consequences affecting both systole and diastole ${ }^{11}$; this deserves full investigation in this patient population because it could potentially affect considerations on routine follow-up with increased surveillance in those patients with particularly unfavorable coupling efficiency. However, the gold standard assessment of VA coupling usually involves invasive pressure-volume loop measurements with conductance catheters. This procedure is not performed routinely in many congenital heart disease centers. Therefore, the purpose of this study was to use a novel noninvasive method, ie, cardiac magnetic resonance (CMR)-derived wave intensity analysis, to evaluate ventricular-arterial coupling efficiency as a consequence of abnormal elastic properties of the ascending aortic wall in patients with TGA palliated with atrial redirection procedures or repaired with ASO. 

Abbreviations and Acronyms
ASO $=$ arterial switch operation
$\mathrm{CMR}=$ cardiac magnetic resonance
$\mathrm{EDV}=$ end-diastolic volume
$\mathrm{EF}=$ ejection fraction
$\mathrm{FCW}=$ forward compression wave
FEW = forward expansion wave
$\mathrm{SV}=$ stroke volume
$\mathrm{TGA}=$ transposition of the great arteries
$\mathrm{VA}=$ ventriculoarterial

\section{MATERIALS AND METHODS \\ Patient Population}

This was a single-center clinical study on 36 patients with dextro-TGA, either palliated with an atrial switch operation $(\mathrm{n}=18 ; 8$ Senning and 10 Mustard procedures) or repaired with ASO ( $\mathrm{n}=18$; all with Lecompte maneuver). In addition, 18 healthy teenagers, screened for assessment of congenital cardiomyopathy, constituted our control group (controls I). Furthermore, a group of healthy volunteers (controls II, $\mathrm{n}=15$ ) was included from a previous study ${ }^{12}$ in order to provide an age-matched control cohort for the older atrial switch TGA group. All demographics are reported in Table 1. Informed consent was obtained in all cases and the study was approved by the institutional research ethics committee.

\section{CMR Imaging}

All participants $(n=54)$ included in this study were examined with CMR imaging as part of their screening. Exclusion criteria for the study were metal artifacts and poor quality CMR. CMR data were acquired with a $1.5 \mathrm{~T}$ scanner (Avanto, Siemens Medical Solutions, Erlangen, Germany). Flow quantification was performed using phase-contrast CMR sequences. Through-plane flow data (approximately 30 milliseconds temporal resolution, interpolated to 30 frames per heart beat) were acquired using retrospective cardiac gating. Retrospectively gated, balanced, steadystate free precession cine images were acquired during breath-hold in the vertical long-axis, 4-chamber, and the short-axis covering the entirety of both ventricles (9-12 slices). Postprocessing was performed using plugins written in house (OsiriX, Pixmeo, Geneva, Switzerland). Systemic ventricular end-diastolic volume (EDV) and end-systolic volume were measured. Stroke volume (SV) and ejection fraction (EF) were calculated from these measurements. Ventricular volumes and stroke volume were indexed (i) for body surface area. Ventricular mass was obtained by manually tracing the epicardial and endocardial borders of the CMR short-axis stack at the end of systole, and the value obtained was then indexed by body surface area $\left(\mathrm{g} / \mathrm{m}^{2}\right)$. An example of CMR data for each study group is shown in Figure 1.

Volunteers in the controls II group did not have a full CMR assessment as part of the research protocol, only flow sequences for wave intensity quantification.

\section{Wave Intensity Analysis}

Wave intensity is a hemodynamic index evaluating the working condition of the heart in relation to the arterial network, ${ }^{13}$ thus providing a valuable mechanistic insight into VA coupling. Although wave intensity has traditionally been derived from simultaneous invasive pressure and velocity measurements, a noninvasive formulation based on simultaneous area and velocity changes has recently been proposed. ${ }^{12}$ This method is based on the semiautomated analysis of phase-contrast MR flow data, from which velocity $(\mathrm{U})$ and area (A) waveforms are derived. Information on $\mathrm{U}$ and $\mathrm{ln}$ $\mathrm{A}$ are combined in a loop; the linear slope in early systole, when no reflected waves are expected, yields the wave speed (c). The $\mathrm{U}$ and $\mathrm{A}$ data are also combined to derive area-based wave intensity, defined as the product of changes in velocity and fractional changes in area, $\mathrm{dI}_{\mathrm{A}}=\mathrm{dU}$ dln A. Furthermore, knowledge of $\mathrm{c}$ allows $\mathrm{dI}_{\mathrm{A}}$ to be separated into its forward and backward components and noninvasively aortic distensibility (D) to be estimated directly from the Bramwell-Hill equation, $\mathrm{D}=1 / \rho \mathrm{c}^{2}$. These steps, summarized in Figure 2, are all integrated in an OsiriX plug-in written in house. ${ }^{12}$

\section{Data Analysis and Statistics}

The following waves can be identified in a typical wave intensity pattern (see Figure 2): a prominent forward compression wave (FCW) at systolic ejection, a small reflected backward compression wave in midsystole, and a forward expansion wave (FEW) in late systole at the time of aortic valve closure. A clinical study has demonstrated that the peaks of FCW and FEW correlate with ventricular contractility (maximum $\mathrm{dP} / \mathrm{dt}$ ) and diastolic relaxation time constant $(\tau)$, respectively. ${ }^{14}$ Peak FCW and peak FEW were thus measured in all cases from the net wave intensity tracings, together with c estimates in order to gather insight into gross changes in D between healthy controls and patients with TGA. These parameters are combined with the hemodynamic data (SVi, EF, EDVi) derived from the CMR examinations.

Data are presented as means \pm standard deviation. Unpaired $t$ test was used to assess differences between the 3 groups. A value of $P<.05$ was considered statistically significant.

\section{RESULTS}

All demographic data are reported in Table 1. Patients with TGA repaired with an atrial switch operation were significantly $(P<.001)$ older than both controls I and patients with TGA repaired with ASO, but were agematched with controls II ( $30 \pm 6$ years in both cases). Considering the age range in each group, no difference in operational era is expected within each TGA cohort. With regard to the ASO cohort, no coronary complications were reported for these patients and only 4 cases presented some trivial $(<5 \%)$ aortic valve regurgitation. Furthermore, blood pressure data showed that none of the patients were hypertensive, with no significant differences in either diastolic or systolic blood pressure between all groups, as reported in Table 1.

Hemodynamic data revealed that patients who had an atrial switch procedure had a significantly lower EF (56\% $\pm 7 \%)$ than controls I $(69 \% \pm 5 \%, P<.001)$ and patients who had an ASO procedure $(66 \% \pm 5 \%, P<.001)$; both TGA cohorts exhibited increased EDVi $(87 \pm 22$ and 86 $\pm 14 \mathrm{~mL} / \mathrm{m}^{2}$, for atrial and arterial switches, respectively) compared with controls I $\left(75 \pm 13 \mathrm{~mL} / \mathrm{m}^{2}, P=.048\right.$ and $P=.016$, respectively).

Further differences were identified between age-matched groups, as well as some intraoperational differences (Table 1). Dimensions of the aortic root were derived from the CMR data at end diastole. It was shown that patients in the ASO group had a larger cross-sectional area $\left(7.3 \pm 2.3 \mathrm{~cm}^{2}\right)$ than controls I $\left(3.6 \pm 1.1 \mathrm{~cm}^{2}, P<.001\right)$ and patients in the atrial switch group had larger crosssectional area than controls II $(5.9 \pm 1.5$ vs $4.3 \pm$ 
TABLE 1. Summary of demographic and CMR data, comparing patients in the ASO group with age-matched controls I, patients in the atrial switch group with age-matched controls II, and intraoperational differences between switch type

\begin{tabular}{|c|c|c|c|c|c|c|c|}
\hline \multirow[b]{2}{*}{ Variable } & \multirow[b]{2}{*}{$\begin{array}{l}\text { Arterial } \\
\text { switch }\end{array}$} & \multirow[b]{2}{*}{ Controls I } & \multirow[b]{2}{*}{$\begin{array}{l}\text { Atrial } \\
\text { switch }\end{array}$} & \multirow[b]{2}{*}{ Controls II } & \multicolumn{3}{|c|}{$P$ values } \\
\hline & & & & & $\begin{array}{c}\text { Arterial vs } \\
\text { controls I }\end{array}$ & $\begin{array}{c}\text { Atrial vs } \\
\text { controls II }\end{array}$ & $\begin{array}{c}\text { Arterial vs } \\
\text { atrial }\end{array}$ \\
\hline \multicolumn{8}{|l|}{ Demographics } \\
\hline Patients, $\mathrm{n}$ & 18 & 18 & 18 & 15 & - & - & - \\
\hline Gender, male/female & $9 / 9$ & $12 / 6$ & $13 / 5$ & $11 / 4$ & .50 & 1.0 & .3 \\
\hline Age, $\mathrm{y} \pm \mathrm{SD}$ & $15 \pm 3$ & $15 \pm 2$ & $30 \pm 6$ & $30 \pm 6$ & .54 & .90 & $<.001^{*}$ \\
\hline $\mathrm{BSA}, \mathrm{m}^{2} \pm \mathrm{SD}$ & $1.7 \pm 0.4$ & $1.7 \pm 0.2$ & $1.9 \pm 0.2$ & $1.9 \pm 0.2$ & .61 & .96 & $.026^{*}$ \\
\hline \multicolumn{8}{|l|}{ CMR data } \\
\hline $\mathrm{HR}, \mathrm{bpm} \pm \mathrm{SD}$ & $75 \pm 10$ & $92 \pm 15$ & $79 \pm 12$ & - & $<.001^{*}$ & - & .13 \\
\hline $\mathrm{SVi}, \mathrm{mL} / \mathrm{m}^{2} \pm \mathrm{SD}$ & $55 \pm 13$ & $52 \pm 9$ & $54 \pm 14$ & $56 \pm 7$ & .43 & .60 & .86 \\
\hline $\mathrm{EF}, \% \pm \mathrm{SD}$ & $66 \pm 5$ & $69 \pm 5$ & $56 \pm 7$ & - & .12 & - & $<.001 *$ \\
\hline $\mathrm{EDVi}, \mathrm{mL} / \mathrm{m}^{2} \pm \mathrm{SD}$ & $86 \pm 14$ & $75 \pm 13$ & $87 \pm 22$ & - & $.017^{*}$ & - & .88 \\
\hline Ventricular mass, $\mathrm{g} / \mathrm{m}^{2} \pm \mathrm{SD}$ & $52 \pm 13$ & $44 \pm 9$ & - & - & $.032 *$ & - & - \\
\hline Aortic area, $\mathrm{cm}^{2} \pm \mathrm{SD}$ & $7.3 \pm 2.3$ & $3.6 \pm 1.1$ & $5.9 \pm 1.5$ & $4.3 \pm 1.0$ & $<.001 *$ & $.001 *$ & $.047 *$ \\
\hline Wave speed, $\mathrm{m} / \mathrm{s} \pm \mathrm{SD}$ & $11.0 \pm 4.7$ & $4.6 \pm 0.9$ & $9.9 \pm 2.6$ & $5.8 \pm 1.3$ & $<.001 *$ & $<.001 *$ & .39 \\
\hline Distensibility, $\times 10^{-3} 1 / \mathrm{mm} \mathrm{Hg} \pm \mathrm{SD}$ & $1.8 \pm 1.6$ & $6.9 \pm 3.6$ & $1.5 \pm 0.8$ & $4.2 \pm 1.5$ & $<.001 *$ & $<.001 *$ & .61 \\
\hline Peak FCW,$\times 10^{-5} \mathrm{~m} / \mathrm{s} \pm \mathrm{SD}$ & $2.1 \pm 1.5$ & $6.3 \pm 2.2$ & $1.7 \pm 0.7$ & $7.7 \pm 5.2$ & $<.001 *$ & $<.001 *$ & .30 \\
\hline Peak FEW, $\times 10^{-5} \mathrm{~m} / \mathrm{s} \pm \mathrm{SD}$ & $0.3 \pm 0.2$ & $0.8 \pm 0.5$ & $0.2 \pm 0.2$ & $1.6 \pm 0.9$ & $<.001 *$ & $<.001 *$ & $.02 *$ \\
\hline \multicolumn{8}{|l|}{ Blood pressure data } \\
\hline Diastolic BP, mm Hg $\pm \mathrm{SD}$ & $68 \pm 13$ & $65 \pm 12$ & $71 \pm 9$ & - & .54 & - & .39 \\
\hline Systolic BP, $\mathrm{mm} \mathrm{Hg} \pm \mathrm{SD}$ & $114 \pm 14$ & $109 \pm 12$ & $112 \pm 12$ & - & .30 & - & .59 \\
\hline
\end{tabular}

$S D$, Standard deviation; $B S A$, body surface area; $H R$, heart rate; $S V i$, indexed stroke volume; $E F$, ejection fraction; $E D V i$, indexed end-diastolic volume; $F C W$, forward compression wave; $F E W$, forward expansion wave; $B P$, blood pressure; $C M R$, cardiac magnetic resonance. $* P<.05$.

$\left.1.0 \mathrm{~cm}^{2}, P=.001\right)$. Aortic root dimensions were also significantly larger in patients in the ASO group compared with patients in the atrial switch group $(P=.047)$. Furthermore, patients in the ASO group also exhibited increased (left ventricular) mass $\left(52 \pm 13\right.$ vs $\left.44 \pm 9 \mathrm{~g} / \mathrm{m}^{2}, P=.032\right)$ and lower heart rate (75 \pm 10 vs $92 \pm 15 \mathrm{bpm}, P<.001)$ compared with the age-matched controls.

Significant differences were measured in terms of wave speed (Table 1). Patients in the ASO group exhibited higher c values than controls $\mathrm{I}(11.0 \pm 4.7$ vs $4.6 \pm 0.9 \mathrm{~m} / \mathrm{s}$, $P<.001)$ and patients in the atrial switch group had significantly higher c values than controls II $(9.9 \pm 2.6$ vs $5.7 \pm$ $1.3 \mathrm{~m} / \mathrm{s}, P<.001)$. There was no significant difference $(P=.39)$ between the 2 TGA cohorts. Differences in wave speed suggest a significantly stiffer proximal aorta in the ASO group than controls I $\left(1.8 \pm 1.6 \times 10^{-3}\right.$ vs $\left.6.9 \pm 3.6 \times 10^{-3} 1 / \mathrm{mm} \mathrm{Hg}, P<.0001\right)$ and in the atrial switch group than controls II $\left(1.5 \pm 0.8 \times 10^{-3}\right.$ vs $4.2 \pm$ $\left.1.5 \times 10^{-3} 1 / \mathrm{mm} \mathrm{Hg}, P<.0001\right)$.

Information on VA coupling was derived from differences observed in the net wave intensity peaks (Table 1). The FCW peak was significantly reduced in patients in the ASO group compared with controls I (2.1 \pm $1.5 \times 10^{-5}$ vs $\left.6.3 \pm 2.2 \times 10^{-5} \mathrm{~m} / \mathrm{s}, P<.001\right)$ and patients in the atrial switch group compared with controls II (1.7 \pm $0.7 \times 10^{-5}$ vs $\left.7.7 \pm 5.2 \times 10^{-5} \mathrm{~m} / \mathrm{s}, P<.001\right)$. FCW did not correlate with variations in $\mathrm{EF}$ in any of the cohorts (controls I, $\mathrm{R}^{2}<0.01, P=.9$; ASO: $\mathrm{R}^{2}=0.04, P=.4$; atrial switch group, $\mathrm{R}^{2}=0.06, P=.3$ ). The FEW peak was also significantly lower in the ASO group than controls I $\left(0.31 \pm 0.16 \times 10^{-5}\right.$ vs $0.78 \pm 0.51 \times 10^{-5} \mathrm{~m} / \mathrm{s}$, $P=.001)$ and in patients in the atrial switch group than controls II $\left(0.18 \pm 0.16 \times 10^{-5}\right.$ vs $1.57 \pm 0.88 \times 10^{-5} \mathrm{~m} / \mathrm{s}$, $P<.001)$. A significant difference $(P=.02)$ was also identified in the FEW peak between atrial and arterial switch procedures $\left(0.18 \pm 0.16 \times 10^{-5}\right.$ vs $0.31 \pm 0.16 \times 10^{-5}$ $\mathrm{m} / \mathrm{s}$, respectively); their FCW peaks were not significantly different $(P=.30)$.

\section{DISCUSSION}

This article assesses hemodynamic and mechanistic differences between 2 groups of patients with TGA (ie, atrial switch and arterial switch repairs) and healthy controls using CMR data. A novel method ${ }^{12}$ for performing wave intensity analysis using CMR data allows information about VA coupling to be derived from phase-contrast sequences acquired for routine flow assessment. In contrast to earlier studies in the literature evaluating hemodynamic capabilities of ASO, ${ }^{15}$ this study is thus entirely noninvasive and gives insight into the interaction between the systemic ventricle and the aorta in all cohorts.

\section{Ventricular Function}

Hemodynamic data derived from CMR examinations highlighted the significantly increased EDVi of the systemic ventricle in patients with TGA, irrespective of the type of 


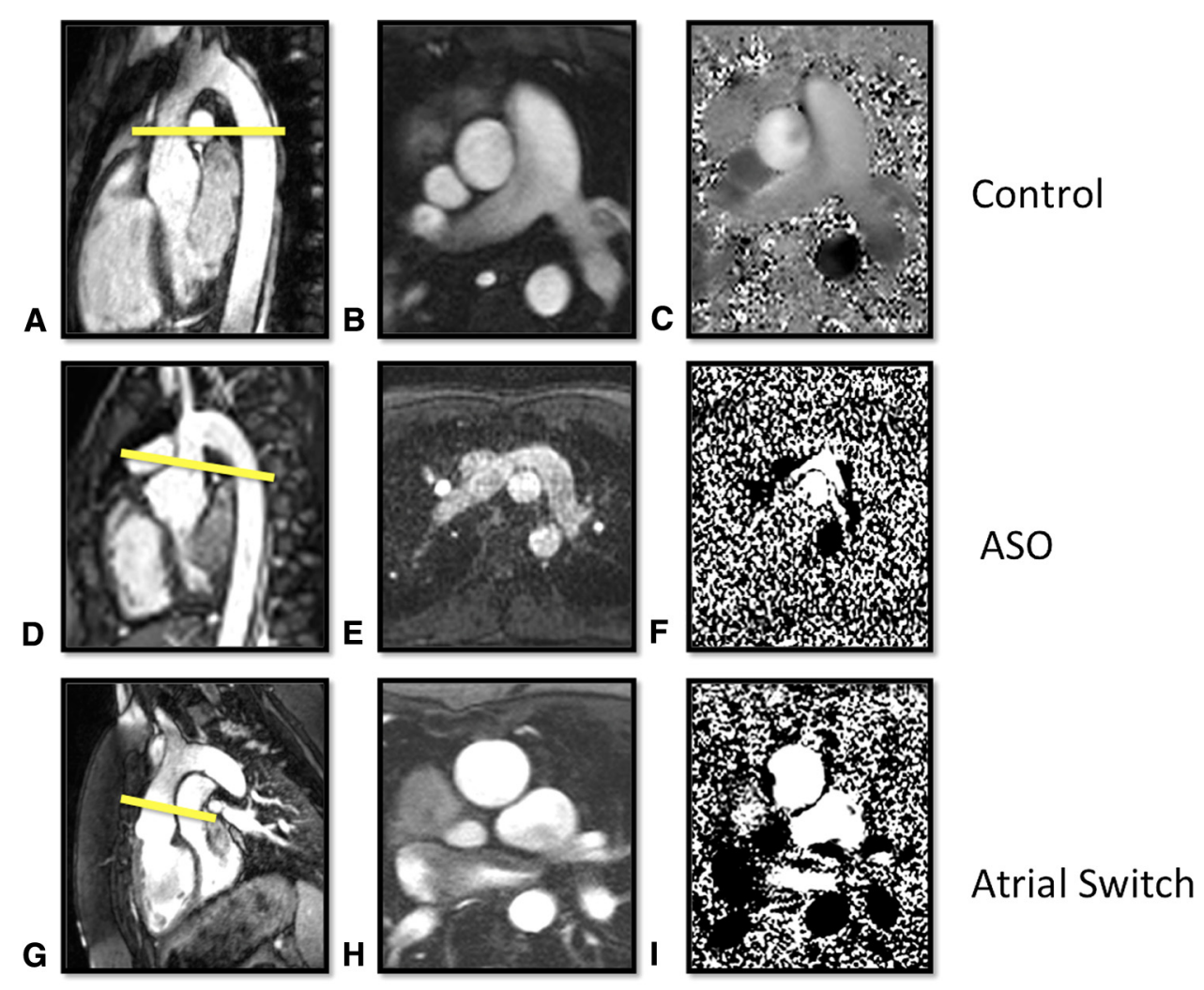

FIGURE 1. Example of cardiac magnetic resonance data acquired in controls (top row), patients with transposition of the great arteries (TGA) repaired with an arterial switch operation (ASO, middle row), and patients with TGA palliated with an atrial switch procedure (bottom row). The whole-heart images $(\mathrm{A}, \mathrm{D}, \mathrm{G})$ show the plane at which phase-contrast flow data were acquired. Phase-contrast magnitude and phase data are also shown (B and $\mathrm{C}$ for controls, E-F for ASO, H-I for atrial switch).

surgical repair. In addition, measurements of EF showed that patients with TGA palliated with atrial switch procedures had reduced EF, whereas patients in the ASO group were comparable with age-matched controls (preserved $\mathrm{EF})$. These findings are in agreement with previous invasive angiographic catheter-based ${ }^{16}$ and recent CMR studies. ${ }^{17}$

\section{Aortic Dimensions, Wave Speed, and Distensibility}

Aortic dimensions derived from CMR highlighted morphologic differences between patients with TGA and controls, with substantially enlarged aortic roots in repaired TGA, especially in patients in the ASO group, whose dimensions were significantly greater than in patients in the atrial switch group, ${ }^{17-19}$

Significant differences in wave speed were measured between patients with TGA and controls. This translates into the patients with TGA having a significantly stiffer aorta, in agreement with previous observations. ${ }^{8,9,20}$ Our values, obtained noninvasively from a wave speed calculation at a single location, rather than with transit-time pulse wave velocity estimation, are consistent with the values in the literature. ${ }^{8,17}$

As wave speed, and hence distensibility, is notoriously an age-dependent parameter, ${ }^{21,22}$ the significant difference in age between the atrial switch cohort and both healthy controls and patients in the ASO group, otherwise agematched, represented a potential confounding factor. This problem was addressed by including an additional control cohort (controls II) in the study, age-matched with the atrial switch cohort. Control group II showed significantly lower wave speed and higher aortic distensibility than patients in the atrial switch group (Table 1). In addition, patients with TGA presented reduced aortic distensibility irrespective of switch type, overriding the physiologic difference caused by increasing age.

A further consideration on aging concerns the ASO group; it is not known whether distensibility will further decrease by the time they reach the same age as the Senning/Mustard cohort. This could potentially have a negative effect on their aortic properties and these patients may be at higher risk of aortic dissection and premature atherosclerosis. This can only be speculated at present, although aortic stiffness has known independent predictive value for allcause and cardiovascular mortalities. ${ }^{23}$

\section{Wave Intensity Analysis}

CMR-derived wave intensity analysis provides insight into VA coupling mechanisms. In particular, the 2 major 

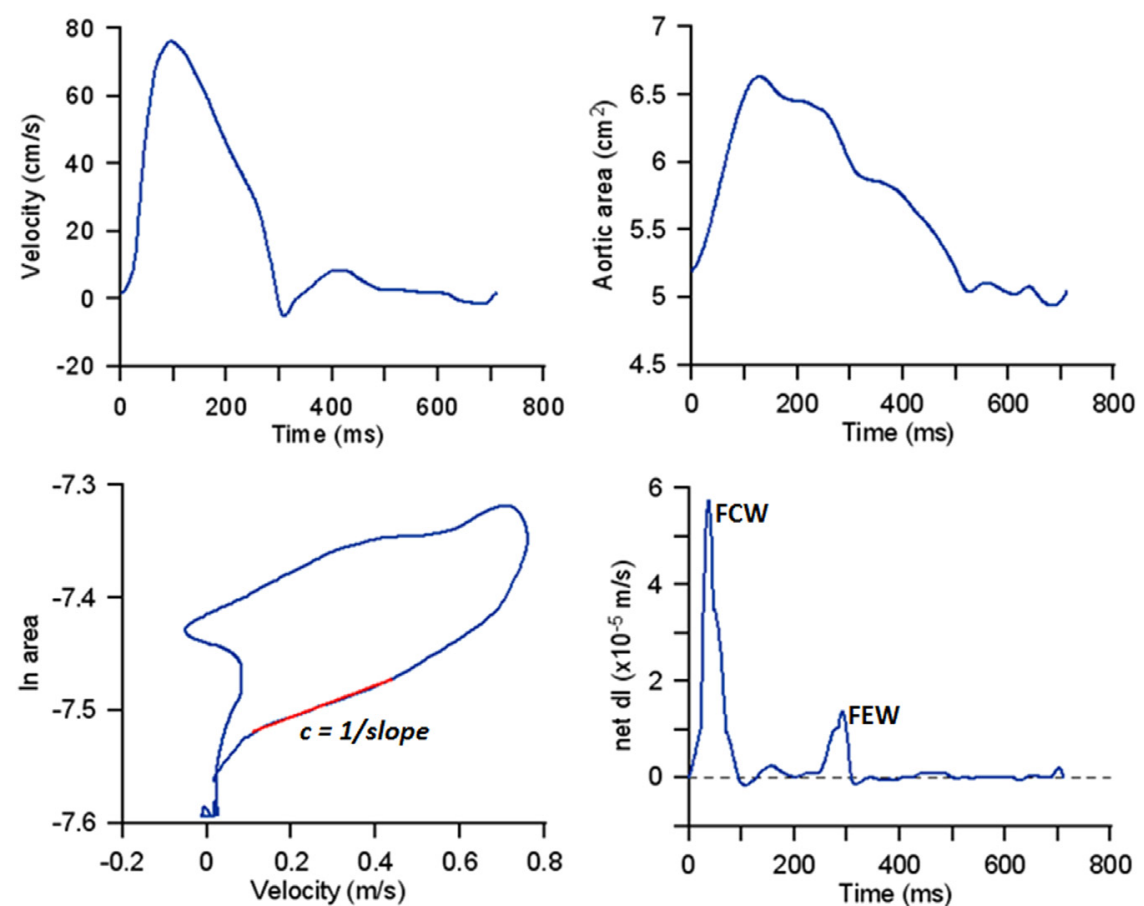

FIGURE 2. Velocity and area data (top) are derived from phase-contrast cardiac magnetic resonance. These are combined for calculating both wave speed c (bottom left) and net wave intensity (bottom right). The wave intensity profile exhibits a dominant forward compression wave in early systole $(F C W)$ and a forward expansion wave at end systole $(F E W)$.

systolic waves (FCW in early systole and FEW at end systole) have been linked to parameters of ventricular performance, ${ }^{14}$ and both exhibit marked differences when compared with controls in the context of this study. The difference in FCW (significantly lower in patients in the TGA cohort) suggests reduced ventricular $\mathrm{dP} / \mathrm{dt}$, whereas the difference in FEW peak (again, significantly lower in patients in the TGA cohort) suggests longer diastolic relaxation, hence less efficient ventricular filling.

In this respect, both switch operations are less efficient compared with normal individuals, likely as a result of the higher impedance resulting from a stiffer ascending aorta impinging on the ventricular-arterial interactions. Although both switches have a low FEW, which inversely correlates with the ventricular relaxation time constant $(\tau)$, ASO seems to fare better when the 2 are compared with respect to diastolic behavior of their systemic ventricles, suggesting an intraoperational difference. However, it must be remembered that the atrial switch cohort has a right ventricle functioning as a systemic ventricle. The systemic right ventricle in patients in the atrial switch group has been shown to have myocardial fibrosis, the extent of which correlates with ventricular function. ${ }^{24}$ Poor function and stiffness might be related to the fibrosis, hence corroborating our findings of a dilated systemic ventricle with poor EF and reduced peak of FCW. Furthermore, with regard to the patients in the ASO group, our findings on VA coupling linked to data on increased ventricular mass on cardiac MR imaging compared with normal individuals ${ }^{8}$ may suggest that the increased mass in these patients is caused by ventricular remodeling. Our data confirmed that patients in the ASO group presented with significantly larger left ventricular mass compared with age-matched controls.

\section{Clinical Perspective, Follow-up, and Implications for Future Research}

In a recent study using CMR imaging, ${ }^{17}$ aortic root dilatation and reduced distensibility were both proposed as possible contributors to diastolic dysfunction in patients after ASO who had a normal EF. Our present study offers a novel CMR-based wave intensity analysis technique to estimate wave speed and distensibility, providing insight into ventricular contraction and relaxation. Although other studies have shown normal EF in patients in the ASO group by standard CMR methods, the FCW component of the wave intensity analysis, which is a surrogate for the rate of pressure change (ventricular contractility), is surprisingly low in patients in the ASO group and those with atrial redirection compared with controls, suggesting that these ventricles are stiffer than normal. In addition, the FEW component of wave intensity analysis, which represents ventricular relaxation and filling, is lower in all patients with TGA than in controls, potentially suggesting diastolic dysfunction in these patients. The development of a reliable and reproducible noninvasive technique to assess for myocardial contractility and relaxation has a 
complementary role to play in assessing for cardiovascular end points of parameters such as EF and could be useful in cross-sectional assessment of these patients. Consequently, the suggested wave intensity analysis method could be put into perspective in the context of planning follow-up for these patients, especially those with suggested unfavorable coupling efficiency.

At present, VA coupling is best assessed using pressurevolume loops; however, as these are obtained using invasive conductance catheter techniques, they are seldom used outside the research environment. ${ }^{25}$ If CMR acquisition wave intensity analysis information can be shown to be an accurate and reproducible measure of VA coupling, then this could become part of routine clinical assessment.

Our results, in agreement with Voges and colleagues, ${ }^{17}$ suggest that patients undergoing ASO should probably be followed up more frequently than is currently believed. Although other noninvasive techniques could be used to assess VA coupling (real-time three-dimensional echocardiography and arterial tonometry ${ }^{26}$ ), these techniques have never been shown to work in this patient population, and are not performed as part of routine clinical assessment, whereas CMR assessments are routine in many centers for the follow-up of patients after treatment for TGA and the addition of a wave intensity assessment to such protocols would be straightforward.

Other groups of patients with congenital heart disease could be studied using this technique. A recent study has applied it to a small cohort of patients with singleventricle physiology to show the impact of patching at the time of a Norwood procedure on VA coupling. ${ }^{27}$ Potentially, this technique could be expanded into other lesions, including right-sided lesions, where right ventricularpulmonary arterial interactions are worthy of investigation, eg, repaired tetralogy of Fallot or patients with pulmonary hypertension. In this context, the time investment required for this kind of acquisition and analysis should also be taken into account. At present, this method does not require any additional acquisition but can be performed on a routinely acquired phase-contrast flow sequence during CMR examination, and provided image quality is good, wave intensity data can be extracted within 10 minutes during the postprocessing phase.

\section{Limitations}

One limitation of this study is the significant difference in age between the older atrial switch cohort and the younger controls and patients in the ASO group, inherently due to the historical evolution of surgery for treating TGA. As discussed, this was addressed by adding a second cohort of controls, age-matched to the patients in the Mustard/Senning cohort (Table 1).

A second limitation of this study is inherent to the patient populations, whereby patients in the arterial and atrial switch groups present with different subaortic ventricles (left ventricle vs right ventricle). Comparisons between the 2 groups should therefore be drawn with caution. The amplitude of the measured waves confirmed the expected finding of reduced systemic right ventricular function in patients in the atrial switch group. Causes of the reduced systemic right ventricular function in these patients are multifactorial and well established, including the inability of the right ventricle to deal with the systemic load to which it is subjected, inadequate coronary artery supply to deal with the hypertrophied right ventricle, and the presence of fibrotic changes in the right ventricle after the atrial switch proven on CMR-based late gadolinium enhancement. ${ }^{24}$

Out-of-plane motion in the CMR flow sequences may represent a problem for the area estimates. Nevertheless, this movement has been quantified in the range of less than $1 \mathrm{~cm},{ }^{28,29}$ and assuming that the ascending aorta does not taper significantly in that region and that regional wall properties remain constant, area measurements should not be substantially affected.

This study used retrospective data and is cross-sectional in design, with a relatively small number of patients. Because of the retrospective nature of the data, CMR data are of Cartesian type ( $\sim 30$ milliseconds temporal resolution). This represents a methodological limitation. We have advocated a high temporal resolution ${ }^{12}$ to implement this noninvasive methodology. Considerations on net wave intensity, and thus VA coupling, are not affected and this study was a first attempt at looking at these populations noninvasively. However, low temporal resolution data are suboptimal for estimation of wave speed, which indeed would require high temporal resolution. Nevertheless, differences between groups (gross changes in D between the groups) still indicate an effective reduction of aortic elasticity in the switches. Furthermore, values for wave speed and distensibility are in agreement with data from the literature. These represent preliminary indications on ventricular function after TGA repair obtained noninvasively. In the future, it will be desirable to perform a prospective study on larger cohorts, prospectively acquiring high temporal resolution data.

\section{CONCLUSIONS}

Using CMR-derived wave intensity analysis, we have observed that VA coupling is compromised in patients with repaired TGA, irrespective of switch type. Reduced net wave intensity was observed in both repair types, both exhibiting reduced FCW (surrogate for ventricular contractility) despite patients in the ASO group having a normal EF. Intraoperational differences should be gathered with caution, taking into account the differences in subaortic ventricle and age between the 2 groups. Ventriculoarterial coupling in patients in the ASO group is lower than might be expected when the clinical outcomes for patients in the 
ASO and atrial switch groups are compared. Although longterm outcomes are difficult to predict without speculating, it will be interesting to evaluate the effect of potential further stiffening of the aorta on VA coupling in patients after ASO, prospectively using high-resolution acquisitions. Wave intensity could turn out to be a useful biomarker in this context, but this should be evaluated in larger cohorts of patients.

\section{References}

1. Mustard WT. Successful two-stage correction of transposition of the great vessels. Surgery. 1964;55:469-72.

2. Senning A. Surgical correction of transposition of the great vessels. Surgery. 1959;45:966-80.

3. Konstantinov IE, Alexi-Meskishvili VV, Williams WG, Freedom RM, Van Praagh R. Atrial switch operation: past, present, and future. Ann Thorac Surg. 2004; 77:2250-8.

4. Jatene AD, Fontes VF, Paulista PP, de Souza LC, Neger F, Galantier M, et al. Successful anatomic correction of transposition of the great vessels. A preliminary report. Arq Bras Cardiol. 1975;28:461-4.

5. Lecompte Y, Zannini L, Hazan E, Jarreau MM, Bex JP, Tu TV, et al. Anatomic correction of transposition of the great arteries. J Thorac Cardiovasc Surg. 1981; 82:629-31.

6. Warnes CA. Transposition of the great arteries. Circulation. 2006;114:2699-709.

7. Culbert EL, Ashburn DA, Cullen-Dean G, Joseph JA, Williams WG, Blackstone EH, et al. Quality of life of children after repair of transposition of the great arteries. Circulation. 2003;108:857-62.

8. Grotenhuis HB, Ottenkamp J, Fontein D, Vliegen HW, Westenberg JJ, Kroft LJ, et al. Aortic elasticity and left ventricular function after arterial switch operation: MR imaging-initial experience. Radiology. 2008;249:801-9.

9. Rutz T, Max F, Wahl A, Wustmann K, Khattab K, Pfammatter JP, et al. Distensibility and diameter of ascending aorta assessed by cardiac magnetic resonance imaging in adults with tetralogy of fallot or complete transposition. Am J Cardiol. 2012;110:103-8.

10. Lalezari S, Mahtab EA, Bartelings MM, Wisse LJ, Hazekamp MG, Gittenbergerde Groot AC. The outflow tract in transposition of the great arteries: an anatomic and morphologic study. Ann Thorac Surg. 2009;88:1300-5.

11. Nichols WW, O’Rourke MF, Avolio AP, Yaginuma T, Pepine CJ, Conti CR. Ventricular/vascular interaction in patients with mild systemic hypertension and normal peripheral resistance. Circulation. 1986;74:455-62.

12. Biglino G, Steeden JA, Baker C, Schievano S, Taylor AM, Parker KH, et al. A non-invasive clinical application of wave intensity analysis based on ultrahigh temporal resolution phase-contrast cardiovascular magnetic resonance. J Cardiovasc Magn Reson. 2012;14:57.

13. Parker KH. An introduction to wave intensity analysis. Med Biol Eng Comput. 2009; 47:175-88.

14. Ohte N, Narita H, Sugawara M, Niki K, Okada T, Harada A, et al. Clinical usefulness of carotid arterial wave intensity in assessing left ventricular systolic and early diastolic performance. Heart Vessels. 2003;18:107-11.
15. Wernovsky G, Hougen TJ, Walsh EP, Sholler GF, Colan SD, Sanders SP, et al Midterm results after the arterial switch operation for transposition of the great arteries with intact ventricular septum: clinical, hemodynamic, echocardiographic, and electrophysiologic data. Circulation. 1988;77:1333-44.

16. Borow KM, Arensman FW, Webb C, Radley-Smith R, Yacoub MH. Assessment of left ventricular contractile state after anatomic correction of transposition of the great arteries. Circulation. 1984;69:106-12.

17. Voges I, Jerosch-Herold M, Hedderich J, Hart C, Petko C, Scheewe J, et al. Implications of early aortic stiffening in patients with transposition of the great arteries after arterial switch operation. Circ Cardiovasc Imaging. 2013;6:245-53.

18. Murakami T, Nakazawa M, Momma K, Imai Y. Impaired distensibility of neoaorta after arterial switch procedure. Ann Thorac Surg. 2000;70:1907-10.

19. Mersich B, Studinger P, Lenard Z, Kadar K, Kollai M. Transposition of great arteries is associated with increased carotid artery stiffness. Hypertension. 2006; 47:1197-202.

20. Ladouceur M, Kachenoura N, Lefort M, Redheuil A, Bonnet D, Celermajer DS, et al. Structure and function of the ascending aorta in palliated transposition of the great arteries. Int J Cardiol. 2013;165:458-62.

21. Voges I, Jerosch-Herold M, Hedderich J, Pardun E, Hart C, Gabbert DD, et al Normal values of aortic dimensions, distensibility, and pulse wave velocity in children and young adults: a cross-sectional study. J Cardiovasc Magn Reson. 2012;14:77.

22. Reusz GS, Cseprekal O, Temmar M, Kis E, Cherif AB, Thaleb A, et al. Reference values of pulse wave velocity in healthy children and teenagers. Hypertension 2010;56:217-24.

23. Antonini-Canterin F, Carerj S, Di Bello V, Di Salvo G, La Carrubba S, Vriz O et al., Research Group of the Italian Society of Cardiovascular Echography (SIEC). Arterial stiffness and ventricular stiffness: a couple of diseases or a coupling disease? A review from the cardiologist's point of view. Eur J Echocardiogr. 2009; 10:36-43.

24. Babu-Narayan SV, Goktekin O, Moon JC, Broberg CS, Pantely GA, Pennell DJ, et al. Late gadolinium enhancement cardiovascular magnetic resonance of the systemic right ventricle in adults with previous atrial redirection surgery for transposition of the great arteries. Circulation. 2005;111:2091-8.

25. Derrick GP, Narang I, White PA, Kelleher A, Bush A, Penny DJ, et al. Failure of stroke volume augmentation during exercise and dobutamine stress is unrelated to load-independent indexes of right ventricular performance after the Mustard operation. Circulation. 2000;102(19 Suppl 3):III154-9.

26. Gayat E, Mor-Avi V, Weinert L, Yodwut C, Lang RM. Noninvasive quantification of left ventricular elastance and ventricular-arterial coupling using threedimensional echocardiography and arterial tonometry. Am J Physiol Heart Circ Physiol. 2011;301:H1916-23.

27. Biglino G, Schievano S, Steeden JA, Ntsinjana H, Baker C, Khambadkone S et al. Reduced ascending aorta distensibility relates to adverse ventricular mechanics in patients with hypoplastic left heart syndrome: noninvasive study using wave intensity analysis. J Thorac Cardiovasc Surg. 2012;144:1307-13.

28. Kozerke S, Scheidegger MB, Pedersen EM, Boesiger P. Heart motion adapted cine phase-contrast flow measurements through the aortic valve. Magn Reson Med. 1999;42:970-8.

29. Kilner PJ, Gatehouse PD, Firmin DN. Flow measurement by magnetic resonance: a unique asset worth optimising. J Cardiovasc Magn Reson. 2007; 9:723-8. 